\title{
Reto de la educación superior privada en América latina: entre la expansión y la resistencia
}

\section{Guadalupe Olivier}

\section{(2) OpenEdition}

1 Journals

Édition électronique

URL : https://journals.openedition.org/ideas/382

DOI : $10.4000 /$ ideas.382

ISSN : $1950-5701$

Éditeur

Institut des Amériques

Référence électronique

Guadalupe Olivier, «Reto de la educación superior privada en América latina: entre la expansión y la resistencia », IdeAs [En ligne], 2 | 2012, mis en ligne le 03 octobre 2012, consulté le 18 octobre 2022. URL : http://journals.openedition.org/ideas/382 ; DOI : https://doi.org/10.4000/ideas.382

Ce document a été généré automatiquement le 18 octobre 2022

\section{(c) (i) (9)}

Creative Commons - Attribution - Pas d'Utilisation Commerciale - Pas de Modification 4.0 International - CC BY-NC-ND 4.0

https://creativecommons.org/licenses/by-nc-nd/4.0/ 


\title{
Reto de la educación superior privada en América latina: entre la expansión y la resistencia
}

\author{
Guadalupe Olivier
}

1 Los procesos de masificación de la educación superior en América Latina son muy recientes. Es en la década de los noventa del siglo pasado cuando puede observarse el mayor crecimiento de instituciones superiores en la historia educativa de la región. Un fragmento de estas instituciones lo constituye la educación de carácter privado. Su desarrollo creciente y acelerado ha llamado particularmente la atención y corresponde en términos temporales al mismo periodo de la masificación de la educación superior latinoamericana. En muchos países coincide que el mayor número de establecimientos corresponden a la educación privada, aunque todavía la mayor atención del estudiantado sigue dentro de las instituciones públicas. Cada país tiene su propia historia universitaria, de tal forma que el sistema privado adquiere una configuración específica a pesar de que las orientaciones del cambio educativo han sido muy similares para todos los países de la región.

2 En este artículo se hace referencia al sistema de educación superior incluyendo en este término a las instituciones de carácter tanto universitario como no universitario de tipo profesionalizante y politécnico. En este sentido el término es genérico y aglutina a todos los tipos de instituciones superiores, con sus diversas modalidades, tipo de régimen de propiedad y función administrativa (pública o privada). Estos aspectos muestran cómo el sistema latinoamericano se ha caracterizado por su heterogeneidad institucional, su fuerte diversificación y diferenciación. En tal sentido, un estudio del sistema superior de la región es muy complejo porque el acceso a las fuentes de información es limitado. Los estudios que sobre la universidad latinoamericana se han realizado, desde diversos enfoques y agencias, muestran resultados muy relevantes. Sin embargo, el tema de la educación superior privada aún se encuentra en una fase incipiente. ${ }^{1}$ 
3 Este artículo inicia con una caracterización global de las condiciones socioeducativas de la región que permiten comprender las condiciones en las que la educación superior privada se ha desarrollado. A partir de esto puede entenderse el papel que ha jugado el ámbito privado en los años recientes tanto a nivel social como desde la perspectiva de las políticas educativas. Se muestran los antecedentes y condiciones concretas involucradas en el desarrollo de las instituciones, pero también las orientaciones locales y supranacionales tendientes a homogeneizar el comportamiento de la educación superior en la región. Posteriormente se presentan datos generales que establecen las tendencias de crecimiento y configuración del sistema de educación superior privada en América Latina, al mismo tiempo, se presentan ejemplificaciones para ilustrar el proceso de crecimiento, la atención a la matrícula y el tipo de instituciones que hacen del sistema privado latinoamericano un conjunto amorfo, sumamente heterogéneo; lo que explica, en parte, las dificultades para ser estudiado.

4 En el último apartado se muestra, a manera de consideraciones finales, cómo el proceso de privatización no ha sido del todo terso. La historia misma de la conformación de los sistemas universitarios en América Latina, explican en buena medida que su papel social ha sido transformado paulatinamente. De esta forma, aunque la presencia del sistema privado es innegable, la exigencia por educación pública y sobre todo gratuita, han sido elementos que caracterizan las demandas de los grupos en resistencia en Latinoamérica. La expansión del sector privado en educación superior, se ha acompañado de movimientos sociales que han expresado su rechazo hacia el despliegue de las políticas de privatización que entre otros aspectos, han dado oportunidad a la creación de instituciones lucrativas. El conjunto de reflexiones que se presentan en este documento tiene el propósito de establecer puntos clave que permitan abordar estudios más profundos sobre un tema de la mayor actualidad y relevancia en los procesos de reforma y cambio del sistema de educación superior.

\section{Contexto socioeducativo en América Latina y las estrategias de la política educativa para la educación superior}

5 Diversos estudios de organismos como el Banco Mundial entre otros, sostienen que América Latina es la región del mundo con mayores desigualdades sociales, entre ellas destaca la dificultad de las mayorías para acceder a la educación. El sistema de educación superior en la región es muy joven. En realidad inició como un sistema exclusivamente universitario en donde se formaban las élites. El paso de una universidad reservada a los grupos privilegiados a un sistema de apertura más democrática es uno de los saltos más relevantes en el siglo XX. Esto explica hasta cierto punto el tipo de configuración de las instituciones en medio de un contexto social y económico con muchas carencias. El papel que ha jugado la universidad latinoamericana a lo largo del periodo de su ampliación hacia los diversos sectores de la sociedad, fue más allá del interés por la formación profesional. Este aspecto es tan solo una parte que privilegiaba la capacitación y mejoramiento formativo de los nuevos profesionistas que necesitaban las economías emergentes. Las instituciones superiores también se han constituido como elementos fundamentales para avanzar en la construcción de sociedades más equilibradas que permitan además del desarrollo económico, también el reconocimiento y preservación de las identidades culturales 
(Stalliveri, 2007:79). En tal sentido, la universidad latinoamericana se mantuvo al menos en los primeros dos tercios del siglo $\mathrm{XX}$, como una institución de carácter eminentemente social y por lo tanto de interés público.

\section{Etapas de las evoluciones de las universidades latinoamericanas}

6 Hay tres momentos claves en la historia de las universidades latinoamericanas. En la primera reforma, a principios del siglo XX, el punto nodal se centró en la autonomía y co-gobierno universitario, que implicó nuevas formas de reorganización tanto académica como administrativo-financiera. El propósito o misión universitaria en este contexto fue la de fortalecer la configuración de sociedades modernas donde las elites ilustradas llevarían la vanguardia en la conformación de nuevas sociedades. La Reforma de Córdoba ${ }^{2}$ en 1918, planteó la gratuidad como medio de acceso y la lucha por la democratización. Ambos son los factores más significativos que han definido a la universidad latinoamericana hasta la década de los ochenta (Rama, 2007). La segunda reforma, en los años setenta, tiene la intención de ampliar la oferta educativa: se produce un crecimiento de instituciones superiores muy diferenciadas que no necesariamente son de tipo universitario. Aquí se ubica el despliegue de instituciones politécnicas y otras modalidades más especializadas que le dan una mayor cobertura al sistema público. En la tercera reforma, desde los años noventa se observa el proceso más importante de masificación e internacionalización de la educación superior latinoamericana. Se realiza, en parte, a travès del aumento de instituciones privadas. Existen un conjunto de elementos socio-educativos que hacen necesario el crecimiento del sistema. Sin duda la reconfiguración demográfica en Latinoamérica es uno de los elementos importantes, el grupo etario entre 18 y 23 años se convirtió en una masa significativa que ejerció una enorme presión para obtener estudios superiores, especialmente en la década de los noventa. Baste decir que en 1994 la región contaba con 7 millones 544 mil estudiantes matriculados, y para el año de 2003, se incrementó a 13 millones 851 mil. Entre ellos se destacan los sectores emergentes que históricamente habían sido marginados de la educación superior (IESALC-UNESCO, 2006). Entre estos nuevos grupos sociales, se encuentran los estudiantes indígenas. Muchos países de la región modificaron en los años noventa sus bases constitucionales incorporando las nociones de multiculturalismo y diversidad como aspectos claves para el reconocimiento de los distintos y numerosos grupos indígenas. Poco a poco se iniciaron acciones que promovieron la incorporación de jóvenes indígenas al nivel de educación superior, implementándose estrategias y programas con la perspectiva multiétnica apoyando a estos jóvenes a través de becas, cursos propedéuticos e incluso la creación de instituciones de carácter específicamente indígena ${ }^{3}$.

7 Este no es un tema menor, ya que en términos globales la población indígena de América Latina es aproximadamente de 50 millones de personas, con condiciones económicas muy adversas impactando de manera fundamental en su acceso a la educación. Uno de los últimos estudios del Banco Mundial en países de la región donde la población indígena es relevante: Brasil, Guyana, Guatemala, México, Bolivia, Chile y Perú, muestran que el ingreso económico de indígenas es inferior al de los blancos en un porcentaje de 35 a $65 \%$. De la misma forma los niveles de ingreso globales muestran un panorama crítico. Según Perry, Ferreira y Walton coordinadores del informe, el decil más rico en la región se queda con el $48 \%$ del ingreso total mientras el decil más pobre solo con el $1.6 \%$. En países desarrollados, el decil más rico queda con el $29.1 \%$ y el 
inferior con el 2.5\%. Bajo la utilización del "Índice de Gini" ${ }^{4}$ los investigadores del Banco Mundial descubrieron que el país con menor desigualdad de América Latina es Uruguay. No obstante su nivel de desigualdad es mayor que el del país más desigual de Europa Occidental (Banco Mundial, 2003).

8 A pesar de la incorporación de instituciones con una perspectiva de educación intercultural indígena y bilingüe, los diagnósticos anuncian que nos encontramos frente a un sistema de escolarización de menor calidad que el resto de las modalidades de educación superior. Pero más allá del tema de la calidad de las instituciones, el impacto de la nueva demanda por estudios superiores se convirtió en un escenario inédito en la región. Las políticas de ampliación de la cobertura frente a la fuerte demanda rebasaron la capacidad de atención de la inversión pública colocándose la apuesta en la inversión de capitales privados. Ademas las políticas y programas que impulsaron desde los setenta en toda la región los estudios de nivel secundario y bachillerato, generaron al mismo tiempo nuevas expectativas educativas relacionadas con la idea de movilidad social. Puede decirse entonces que en esta década se inició el proceso que más tarde derivaría en la fuerte demanda de estudios superiores en los noventa. En términos generales, en los noventa, América Latina pasó de un modelo universitario de élite bastante homogéneo y cerrado a un sistema con características más populares, de índole masiva. Se incorporan estudiantes de diversos sectores, incluyendo al indígena que prácticamente nunca había tenido posibilidades de incorporarse a la universidad. Incluso, en el caso de Brasil por ejemplo, hay sectores indígenas que acuden a la enseñanza privada (Hall y Patrinos, 2005; Rama, 2007).

\section{El fortalecimiento de la oferta privada}

9 Por otra parte los estudios de agencias multilaterales tuvieron mucho impacto sobre las políticas educativas de todos los países. Aunque en diferente medida, todos los países de la región respondieron a las recomendaciones de dichos organismos. Sobre todo, el estado adoptó un nuevo papel frente al sistema de educación superior: se convirtió en un regulador y vigilante a través de la creación de agencias de evaluación, que al mismo tiempo han funcionado como mecanismos de fiscalización e incentivación económica extraordinaria. De cualquier forma, el crecimiento del sistema de educación superior logró una cobertura bruta aproximada del $30 \%$ hacia los primeros años del presente siglo manteniéndose hasta el año 2011 (Banco Mundial, 2007/2011; Rama, 2007: 21). Antes de la década de los noventa los recursos financieros que impulsaron la creación de instituciones provenían en su mayor parte de recursos públicos. Es a partir de la tercera reforma que se incorporaron nuevos actores, empresarios principalmente, en la fundación de nuevas instituciones. Si bien puede reconocerse cierto incremento presupuestal del erario público, la presencia de inversiones privadas inició una fuerte presencia en el sistema. Uno de sus corolarios fue la erogación económica directa de las familias sobre el pago de colegiaturas y otros gastos que ya no fueron subvencionados por el estado. Para la tradición del modelo de universidad latinoamericana este aspecto representó un giro fundamental.

10 Entre los elementos que contribuyeron al fortalecimiento de la oferta privada, se encuentra la aplicación de estrategias de contención al acceso al sistema de educación superior pública a través de variados mecanismos dependiendo de las políticas locales. Ante un contexto de alta demanda por estudios superiores, el sistema privado tendió a 
absorber un fragmento que quedó fuera de las instituciones superiores públicas. Hacia principios del siglo XXI, la educación superior privada en América Latina cubría el 47\% de la matrícula (Rama, 2007), aunque es importante precisar que este porcentaje tiene variaciones según las particularidades de cada país. Ya en este periodo existe una diferenciación concreta de las distintas ofertas de educación superior, que van desde la dualidad pública-privada, la universitaria-no universitaria y la de calidad-baja calidad, que en el desarrollo del sistema de educación superior hasta el segundo tercio del siglo XX no se había dado. Dentro de la reconfiguración de las instituciones hay que tomar en cuenta también la regionalización interna. En el pasado había un fuerte desplazamiento de los estudiantes de las provincias hacia las capitales o ciudades de mayor desarrollo para ingresar a las universidades. Ahora la masificación implicó también la creación de instituciones públicas y privadas en sus provincias. En el terreno de las instituciones privadas, sobre todo las de carácter lucrativo, encontraron en estos lugares geográficos nichos de mercado ideales para su desarrollo.

11 La presencia de los establecimientos privados en América Latina se constituye como un factor relevante a discutir, entre otras cosas por sus propias condiciones socioeconómicas. En la actualidad la cobertura de educación en la región está entre el 37 y $38 \%$ (IESALC-UNESCO, 2006), en buena medida debe atribuírsele al papel que han jugado en las décadas recientes las aportaciones familiares. El punto medular a tomar en cuenta es el contexto de los ingresos económicos y los niveles de vida en Latinoamérica que hacen del tema de la financiación de los estudios superiores un aspecto fundamental ${ }^{5}$. Esto significa que hay un esfuerzo real de la población por sostener estudios superiores sobre todo si se trata de una institución privada debido a que, a diferencia de otros países como en Estados Unidos ${ }^{6}$, la educación privada suele ser más cara que la pública. A pesar de la apuesta por este tipo de instituciones, se encuentran resultados contradictorios. Según estudios de Claudio Rama (2007:21) el aumento de la matrícula en educación privada ha ido en aumento pero no así los ingresos per cápita, lo que explica las dimensiones del esfuerzo económico individual por lograr sostener la educación profesional. Los datos que ofrece este autor son muy reveladores, en la última década el producto bruto por individuo fue aproximadamente de $3,7 \%$ y el crecimiento de la región de $18,3 \%$, pero la matrícula creció sobre el $63,2 \%$, de éste porcentaje cerca del $50 \%{ }^{7}$ corresponde a la educación privada.

La creación de instituciones públicas no se ha abandonado por completo, pueden distinguirse dos formas, una es la apertura de instituciones nuevas principalmente en las provincias, tal es el caso de Perú, México, Brasil, Bolivia y Venezuela. Otra forma ha sido la ampliación regional de instituciones ya establecidas a fin de ofrecer mayor cobertura fuera de las capitales de los países, un ejemplo de ello es Guatemala, República Dominicana ${ }^{8}$, Honduras y también México9. Pero la ampliación hacia sus respectivas provincias se acompañó fundamentalmente de la oferta del sector privado; puede verse una combinación de ampliación y nuevas creaciones de establecimientos de educación superior tanto públicos como privadas, significativamente en países como Perú y Venezuela (ibid: 31,32). El gasto público hacia la educación tiene muchas variaciones entre los países de la región, naciones como Brasil destinan el $16.1 \%$ del gasto gubernamental, mientras Costa Rica dedica el $23.1 \%$ por citar un par de ejemplos (Banco Mundial, 2007/2011). Uno de los problemas que se destacan en este proceso es la disminución de la calidad en términos infraestructurales, tecnológicos, curriculares y docentes, esto produce un sistema sumamente variado y en algunos casos desestructurado. La operación irrestricta de algunas instituciones con un exceso en la 
orientación mercantilista tendió a difuminar los intentos de regulación del sistema. En la mayor parte de los países latinoamericanos puede distinguirse este fenómeno, pero el caso peruano es uno de los que más sobresale al respecto.

13 Con todos los elementos que se han presentado hasta ahora, es muy interesante contrastar dos elementos que se encuentran en tensión constante: uno es el reconocimiento de la necesaria ampliación de la matrícula en estudios superiores; el otro elemento es que los mecanismos que se han adoptado desde las políticas educativas, se han centrado en un entre-juego que vincula la inversión pública en la creación de nuevas instituciones (principalmente de tipo tecnológico) y la apertura hacia la inversión privada (nacional y transnacional). La ampliación de la cobertura, incluyendo el posgrado, no necesariamente fue acompañado de un proceso de elevación de la calidad en la formación profesional. Las grandes diferencias entre las capitales y las provincias siguen presentándose de manera importante. Sin embargo, en países como México cerca de la mitad de estudiantes de posgrado estudia en una institución privada.

\section{Tendencias generales de expansión de la educación superior privada en la región}

El desarrollo de la educación privada tendió a flexibilizarse desde finales de los setenta, pero es en los noventa cuando se observa con claridad la cúspide del desarrollo de la educación superior privada en América Latina (Olivier, 2007: 201). Entre mediados y finales de ésta década existían aproximadamente 700 mil estudiantes inscritos en el servicio privado, pero hacia el año 2000 se observa un incremento de $135 \mathrm{mil}$ estudiantes más matriculados por año, lo que en términos absolutos significó $835 \mathrm{mil}$ estudiantes en total solamente en el año 2000. Puede observarse que en un periodo de entre 1994 y el 2003 el número de estudiantes inscritos en las instituciones privadas aumentó en un $83 \%$. En el caso de México, hasta antes de la década de los noventa el tipo de instituciones privadas tenían características más o menos homogéneas y atendían a un sector de la población también con características muy similares. En los noventa el escenario socioeducativo tendió a modificarse y esto marcó un nuevo sentido a la creación de servicios de educación superior de tipo privado. Entre los más importantes puede ubicarse la emergencia de nuevos sectores de la sociedad que inusitadamente comenzaron a demandar educación privada, se incluye en esta categorización sectores de las clases medias y otros con condiciones económicas menos favorecidas.

Tabla 1 : Cobertura Relativa de la Educación Superior Privada

en América Latina

\begin{tabular}{|l|l|l|}
\hline \multicolumn{2}{|l|}{} \\
\hline Años & $\%$ de participación privada & Incremento anual \\
\hline 1994 & $38,5 \%$ & $100,0 \%$ \\
\hline 1995 & $39,5 \%$ & $2,6 \%$ \\
\hline
\end{tabular}




\begin{tabular}{|l|l|l|}
\hline 1996 & $40,4 \%$ & $2,3 \%$ \\
\hline 1997 & $41,3 \%$ & $2,2 \%$ \\
\hline 1998 & $42,5 \%$ & $2,9 \%$ \\
\hline 1999 & $44,0 \%$ & $3,5 \%$ \\
\hline 2000 & $44,9 \%$ & $2,0 \%$ \\
\hline 2001 & $45,4 \%$ & $1,1 \%$ \\
\hline 2002 & $46,1 \%$ & $1,5 \%$ \\
\hline 2003 & $46,6 \%$ & $1,0 \%$ \\
\hline 2004 & $47,0 \%$ & $0,8 \%$ \\
\hline 2005 & $47,5 \%$ & $1,0 \%$ \\
\hline 2006 & $47,8 \%$ & $0,6 \%$ \\
\hline 2007 & $48,2 \%$ & $0,8 \%$ \\
\hline
\end{tabular}

Fuente: Rama (2007)

15 Un elemento importante a tomar en cuenta en este proceso fue el de la ampliación del rango de edad, donde se incluye el fragmento de estudiantes que al mismo tiempo son trabajadores. Estos han jugado un papel determinante en el crecimiento de la oferta privada en Latinoamérica pues estas instituciones cubrieron una demanda latente que la estructura de las instituciones públicas no pudo atender. Las instituciones privadas encontraron en el trabajador-estudiante un interesante nicho de expansión, ofreciéndoles horarios de clase flexibles, nocturnos y sabatinos considerándose un perfil distinto al del estudiante tradicional. Aquí se considera a un adulto con responsabilidades familiares, donde su interés por los estudios profesionales está ligado a su ámbito laboral. En este sentido, consideraron titulaciones accesibles con ciclos más cortos y procesos más rápidos de egreso. En el Caribe por ejemplo, el $70 \%$ de los estudiantes trabajan y en Argentina el 11\% tienen más de 30 años de edad (IESALC/ UNESCO).

Al mismo tiempo puede observarse un incremento muy importante de mujeres dentro de la educación superior en general pero especialmente en las instituciones privadas. $\mathrm{E}$ sector privado muestra tipos institucionales muy diversos que intentan cubrir las diferentes formas en que se demanda la educación privada. Hay un desplazamiento de la idea tradicional de estudiante, por la figura de cliente al que debe "vendérsele" un modelo ideal que cubra sus particulares necesidades de formación profesional. Dentro de las consecuencias se observa una importante heterogeneidad en el tipo de servicios que se ofrecen y en una calidad muy diversa de sus programas profesionales y de posgrado en el que se fomentó una dinámica mercantilizada de la educación superior. La competencia por la captación de estudiantes-clientes dió una dinámica distinta al sistema. Con ello se rompen los viejos esquemas de educación universitaria para las 
élites, que en América Latina estaba representada por escuelas religiosas, dominantemente católicas.

Desde el punto de vista del pago por derechos de matrícula, poco a poco la educación superior privada comenzó una metamorfosis y aunque se ha caracterizado por su amplia heterogeneidad, a grandes rasgos pueden observarse tres esferas distintas de escolarización claramente delimitadas: la escuela para los grupos de mayor capacidad económica, algunas de buena calidad y con los costos más altos, las escuelas para sectores intermedios con capacidades económicas más limitadas y las instituciones de absorción de demanda con menores niveles académicos y con costos más accesibles. Es importante puntualizar aquí que la dinámica en las instituciones públicas también adoptó nuevas formas. Lo que puede decirse del sistema en su conjunto es que hay dinámicas de polarización socioeducativa que marcan ciertas tendencias de acceso en cada tipo universitario. Por una parte se observa en las instituciones privadas, escuelas para las élites con altos costos y otras más accesibles que absorben a la población que no logra ingresar a las instituciones públicas. Lo que es claro en toda la región es que a pesar de que en algunos países se crearon instituciones públicas el ajuste de la oferta se orientó a la expansión de la educación privada.

Gráfica 1: Matrícula en porcentajes de Instituciones de Educación Superior Privada (IES) en América Latina

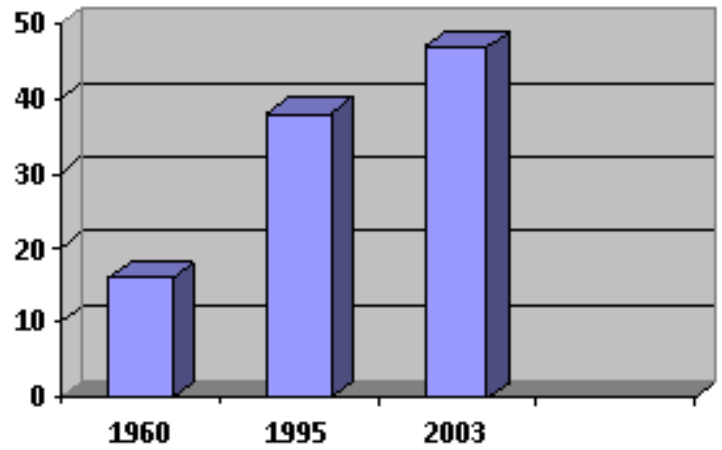

$\square \%$ matrícula en IES

privadas

FUENTE: ELABORACIÓN PROPIA CON DATOS DE IESALC-UNESCO, 2006

educación superior privada en la actualidad cuenta con el 52\% de los estudiantes de total que asisten a las instituciones superiores (SITEAL, 2011: 5). No obstante los ritmos de crecimiento entre el sector público y privado están tendiendo a semejarse, ésta situación fue distinta en los noventa cuando se hizo evidente un fenómeno de contención en el crecimiento de la incorporación de estudiantes a la educación superior pública. A excepción de Cuba, todos los países de América Latina cuentan con educación superior privada aunque con distintas configuraciones y proporciones. Se considera un sector grande de educación privada cuando absorbe a más del 50\% de la matrícula total de estudiantes en la educación superior. Aquí se ubican países como Brasil, República Dominicana, El Salvador, Chile y Colombia - en estos dos últimos países la educación superior pública no es gratuita a diferencia de los primeros tres. El sector privado mediano es aquel que tiene entre el $25 \%$ y 50\% de estudiantes en este sector, aquí se encuentran Nicaragua, Paraguay, Perú, Venezuela, Guatemala y México. En estos casos 
se cuenta con un sector público grande y a excepción de Guatemala y México los primeros cuatro son totalmente gratuitos. Un sector privado pequeño es el que tiene menos del 25\% de su matrícula inscrito en éstas instituciones: Costa Rica y Bolivia con un sector público no gratuito y Ecuador, Argentina, Panamá, Honduras y Uruguay con instituciones públicas gratuitas (López, 2009: 246).

Tabla 2 : Cobertura privada en educación superior. Países de América Latina (2004)

\begin{tabular}{|l|l|}
\hline País & Índice relativo \\
\hline Chile & $75,1 \%$ \\
\hline Brasil & $71,7 \%$ \\
\hline Colombia & $58,3 \%$ \\
\hline Perú & $45,2 \%$ \\
\hline México & $33,8 \%$ \\
\hline Panamá & $29,9 \%$ \\
\hline Argentina & $23,5 \%$ \\
\hline Uruguay & $9,7 \%$ \\
\hline Cuba & $0,0 \%$ \\
\hline
\end{tabular}

Fuente: Pereyra (2008:138)

19 Aun cuando se ha mostrado un fuerte crecimiento del sistema de educación superior desde finales de los ochenta hasta la fecha, esto no significa que América Latina haya alcanzado un óptimo nivel de cobertura, ni mucho menos lograr un impacto en su desarrollo estructural. Los niveles de desigualdad entre los países de la región muestran que la alternativa de crecimiento por la vía del impulso a la inversión privada no es condición sine qua non para alcanzar niveles democráticos en el acceso a la educación como un derecho social básico. Los temas de la movilidad social por la vía del incremento de estudios profesionales en donde debe comprometerse un esfuerzo individual parecen no haber resultado al final de un par de décadas de implementación de políticas privatizadoras. Un estudio comparado sobre Argentina y Brasil realizado por Paola Ferrari (2005) muestra que el grado de acceso, permanencia y obtención de grado está relacionado estrechamente con los niveles económicos, la escolaridad de los padres y la acumulación de capital social de los estudiantes. Al mismo tiempo, estas condiciones se vinculan al tipo de institución donde ingresa, si es que alcanza esta oportunidad. Significa que hay una perpetuación, por así decirlo, de las condiciones socioeducativas, económicas y culturales que han antecedido la formación del sujeto que aspira a un lugar en la educación superior. Es decir, la diferenciación de la oferta de instituciones está vinculada a las características del sector social que lo demanda. 
Este problema estructural subyace en todos los países latinoamericanos. A pesar de ello, en países como Argentina, con una fuerte tradición de universidad pública, se ha dado un giro a las políticas para el sistema de educación superior desde el periodo 1976-1983 ${ }^{10}$ cuando se opta por una reducción paulatina del financiamiento público orientándose el impulso a la educación superior de tipo privado. Aunque la matrícula en instituciones públicas descendió en un $25 \%$, el número de estudiantes matriculados en las instituciones privadas solo cubrió el 20\% del total nacional (Plotkin, 2006: 44). De hecho fue hasta entrada la década de los noventa cuando se comenzaron a crear nuevamente instituciones superiores de tipo privado, ocho en total entre 1993 y 1997, pero con ello se inició una escalada acelerada de tal manera que hacia el año 2003 existían ya 31 instituciones privadas (Ferrari, 2005: 295). La fuerza de la iniciativa privada en el cono sur se acompañó de un conjunto de acciones, dentro de las políticas universitarias de régimen público, que implicaron cambios sustanciales en torno a lo jurídico, laboral, la gestión, el financiamiento y lo académico. Y aunque se crearon algunas universidades públicas, especialistas del caso argentino como Ferrari (op cit) y Krotsch (2002), afirman que la inversión en estas universidades se debió más a presiones políticas que a una intensión real por invertir en el ámbito público. Se incentivó la inversión privada en diversos sentidos: uno de ellos fue en la diversificación de fuentes de financiamiento de las instituciones públicas a partir de la figura de venta de servicios por asistencia técnica, cursos de capacitación, entre otros. En el terreno jurídico se modificó la Ley de Educación Superior, rompiéndose el principio de gratuidad. Se introduce el concepto de management público y hasta ahora se tiende a evaluar interna y externamente a las instituciones tanto públicas como privadas. Es importante subrayar que siguiendo la tendencia de Latinoamérica en la década de los noventa, decayó de manera importante el presupuesto por alumno matriculado (Ferrari, 2005).

Tabla 3: Matrícula del sistema de educación superior por régimen en índices relativos. Países de América Latina (2006)

\begin{tabular}{|c|c|c|}
\hline País & Régimen Público & Régimen Privado \\
\hline Argentina & $77,2 \%$ & $22,8 \%$ \\
\hline Bolivia & $64,8 \%$ & $35,2 \%$ \\
\hline Brasil & $25,8 \%$ & $74,2 \%$ \\
\hline Colombia & $34,9 \%$ & $65,1 \%$ \\
\hline Chile & $0,0 \%$ & $100,0 \%$ \\
\hline Ecuador & $56,7 \%$ & $43,3 \%$ \\
\hline El Salvador & $36,6 \%$ & $63,4 \%$ \\
\hline Guatemala & $53,4 \%$ & $46,6 \%$ \\
\hline Honduras & $75,5 \%$ & $24,5 \%$ \\
\hline
\end{tabular}




\begin{tabular}{|l|l|l|}
\hline México & $70,3 \%$ & $29,7 \%$ \\
\hline Nicaragua & $33,6 \%$ & $66,4 \%$ \\
\hline Paraguay & $41,2 \%$ & $58,8 \%$ \\
\hline Total & $45,4 \%$ & $54,6 \%$ \\
\hline
\end{tabular}

Fuente: SITEAL (2008)

\section{Brasil}

El caso contrario es el brasileño. De hecho Brasil tiene un desarrollo de la educación superior diferente al del resto de América Latina. Cuenta con las universidades más jóvenes de la región. Su primera institución superior fue la Universidad de Río de Janeiro creada en 1920 y de 1930 a 1964 se fundaron más de 20 universidades federales. En la década de los 30 surge la Universidad de Sao Paulo (1934) como institución federal, pública por lo tanto, con una planta docente básicamente europea. Simultáneamente, surgieron un gran número de instituciones privadas con fundamentos religiosos, principalmente católicas y presbiterianas. $Y$ aunque el sistema brasileño siempre haya contado con una importante presencia de instituciones privadas, la década de los noventa se ubica como la fase de mayor auge en su desarrollo, lo que coincide con el proceso de expansión del resto de los países latinoamericanos (Stalivielli, 2007: 82). Brasil cuenta con una base jurídica que identifica, redefine y precisa las formas de propiedad de las instituciones, lo que permite generar procesos de privatización de la esfera pública. Son básicamente tres:

a) propiedad estatal, que implican actividades exclusivas del Estado como la impartición de justicia;

b) propiedad pública no estatal relacionada a actividades consideradas prioritarias pero no exclusivas del Estado, se incluyen los servicios como la salud, la cultura y la educación;

y c) propiedad privada, asociada centralmente a la obtención de beneficios particulares (Bresser-Pereira, 2001).

La incorporación de propiedad pública no estatal, dio la posibilidad de establecer nuevas formas de relación entre el Estado y el mercado a partir de dos fuerzas de control: la social y la competencia en el mercado. Esto se ha fortalecido porque al mismo tiempo se implementaron otras medidas como el otorgamiento del crédito educativo ${ }^{11}$ que se han convertido en puentes de acceso a la educación privada.

Brasil fue uno de los países pioneros en desarrollar procesos de privatización en Latinoamérica con un significado más amplio que implica no solamente la expansión del sector privado sino una suerte de privatización de la educación como bien público. Pablo Gentili lo explica como un proceso de ajuste y reestructuración del sistema de educación superior cuya fase de irrupción tiende a desestabilizar el carácter básicamente democrático de las universidades latinoamericanas en lo que denomina "tecnocratización" de las reformas universitarias vinculadas a la noción de calidad. De esta forma, la privatización del sistema de educación superior en la región cuenta al 
menos con cinco características comunes: 1) reducción del gasto público en educación superior, ciencia y tecnología, 2) aumento de la oferta de inversión privada, 3) transferencia del costo educativo a familias o usuarios del sistema, 4) cobro de aranceles, y 5) subordinación de la actividad académica a las fuerzas del mercado. Estos 5 grandes rasgos se expresan concretamente en elementos estratégicos para reorientar al sistema. No obstante, algunos de ellos aun son ininteligibles como por ejemplo, las políticas de evaluación o el rediseño de los planes de estudio. En ambos ejemplos subyace una intención asociada a la medición de la productividad y a la pertinencia de los programas en el ámbito económico que tienden a subordinar la producción científica y la formación profesional a las demandas del mercado. Esto implica en última instancia, una perspectiva muy acotada de calidad educativa cuyos marcos de referencia se basan en el mérito y la "gerencialización" del proceso educativo. Así, la idea de democratización de la enseñanza superior se desdibuja, el propósito que sostuvo a la universidad latinoamericana como un espacio público de generación de saberes socialmente significativos, se ha desplazado hacia otros ámbitos definidos por los estándares de productividad. Todos estos aspectos asociados a la contención de la inversión en espacios públicos, se contrapone como tendencia general, a las oportunidades de acceso y permanencia de grupos sociales de bajos ingresos a la educación superior (Gentili, 2005: 16, 17).

El caso de Brasil es ilustrativo al respecto. Ya desde los setenta se encuentra la aplicación de una política de productividad académica a través de instrumentos de evaluación y rendición de cuentas al mismo tiempo que una limitación de recursos financieros por parte del gobierno federal. La clasificación clásica de la educación superior, por el tipo de financiamiento, indicaría que Brasil cuenta con dos tipos de instituciones: la pública de tipo federal, estatal o municipal, y la privada, que puede ser de tipo comunitaria, filantrópica, confesional o particular. El Ministerio de Educación de Brasil utiliza los términos público y privado para referirse a los rubros de mantenimiento administrativo y financiero. El sistema público se sostiene del poder público ya sea federal, estatal o municipal. La enseñanza es libre y gratuita, solamente el 3,5\% de los fondos proviene de los estudiantes. En las provincias donde existen universidades estatales el financiamiento proviene de los recursos de los estados, la educación es gratuita, pero no en todos los estados del país existen este tipo de instituciones. Se encuentran principalmente en la región suroeste de Brasil.

Por su parte, las fuentes de financiamiento de las instituciones privadas provienen de las cuotas de los estudiantes, entre el $95 \%$ y $100 \%$. Algunas instituciones pueden obtener recursos adicionales cuando pertenecen a comunidades religiosas, como las Universidades Pontificias Católicas (denominadas PUC's). Y aunque estas instituciones por ser de carácter privado no pueden recibir fondos públicos, sí pueden recibir fondos por proyectos de investigación a través de los posgrados (Stalivielli, 2007: 85). Las instituciones privadas de tipo comunitario pueden ser laicas o religiosas, las de tipo comunitario y laicas no tienen fines de lucro, su financiamiento proviene de los miembros de la comunidad donde se desarrollan aunque su principal sostenimiento es por las cuotas de los estudiantes. Las instituciones de tipo comunitario son diferentes a las de tipo religioso precisamente porque éstas últimas están vinculadas a una congregación religiosa o a una orientación ideológica. Las instituciones comunitarias, filantrópicas y confesionales gozan de exenciones fiscales ${ }^{12}$ porque están caracterizadas jurídicamente como instituciones sin fines de lucro. Las instituciones privadas de tipo particular son aquellas clasificadas con fines de lucro. Son la mayoría en este país. Sus 
propietarios por lo regular no provienen de comunidades educativas propiamente sino de la esfera empresarial o política. Estos establecimientos desde su origen dejaron de ser un bien público, son negocios que se desarrollan a partir de la dinámica del mercado.

Es importante contextualizar el campo socioeducativo brasileño para comprender el tipo de impacto de las instituciones superiores privadas. En la primera década del siglo XXI su sistema educativo atendía a más de 56 millones de estudiantes, de ellos alrededor de 3 millones se ubicaban en la educación superior. En la educación básica se atiende al $88 \%$ de niños y jóvenes en instituciones públicas. El 30\% de la población con 15 años de edad o más, poseen menos de 4 años de estudios. Las cifras anteriores dan una idea del terreno general en el que se desarrolla el sistema superior en su conjunto y las posibilidades de acceder a éste. El gobierno federal brasileño sostiene a 39 universidades, once facultades y once centros de educación tecnológica. Los gobiernos de las provincias también redujeron recursos a las instituciones estatales, tal como lo hicieron desde los noventa para las instituciones federales a fin de derivar la intervención del sector privado (Schwartzman, 2002). Sin duda una de las políticas de redefinición financiera que comparte Brasil con el resto de Latinoamérica es la implementación de estrategias de vinculación para la obtención de recursos complementarios como la venta de servicios por asistencia técnica, consultorías y capacitación. Como ya se ha planteado anteriormente, este factor reformula la visión de las relaciones entre la universidad y el sector productivo. Al mismo tiempo que transforma la visión pública del papel de las universidades, en el marco de una reducción de fondos financieros para el nivel superior.

Hay una paradoja : la fuerte presencia de establecimientos privados ha contribuido a la masificación incorporando a nuevos sectores sociales a la educación superior, pero por otro lado también, ha habido una importante pérdida de calidad. El mayor crecimiento de la educación superior en Brasil en los años recientes ha sido justamente del sector privado denominado jurídicamente como particular, es decir, el fragmento lucrativo de la educación privada. Entre 1999 y 2001 existió una disminución de instituciones de carácter confesional, filantrópico y comunitario del $20 \%$. Caso contrario al fragmento de tipo particular que presentó una expansión del $72 \%$ en ese mismo periodo. El fuerte proceso de privatización de la educación superior en Brasil resulta de una disminución de recursos públicos. En América Latina esta reducción se observa en el deterioro de instalaciones, la caída de salarios y condiciones laborales docentes. En Brasil, como en otros países de la región, el proceso de crecimiento del sector particular fue reconocido e incentivado desde el Ministerio de Educación. Entre 1994 y 2001 el crecimiento del fragmento particular fue del $115,5 \%$, por encima de las instituciones pública federales $(38,4 \%)$, estatales $(53,9 \%)$ y municipales $(-16,6 \%)$. A pesar de este crecimiento Brasil cuenta con los niveles de atención a jóvenes de 18 a 24 años más bajos de América Latina, con tan solo el 11\% (Stalivielli, op cit: 87). Se reconocen al menos tres factores que han posibilitado la demanda de estudios superiores y que es similar a otros países de América Latina: 1) el egreso importante de más estudiantes del nivel bachillerato, 2) la demanda de nuevas y mayores calificaciones para la incorporación a nuevos escenarios laborales, 3) el surgimiento de una cultura que apuesta a la enseñanza universitaria como una forma de mejorar la calidad de vida.

31 El crecimiento del sector privado es proporcional a la capacidad de pago de los estudiantes, en este sentido ha sido fundamental la creación de programas de crédito 
educativo, becas e inversiones estudiantiles. Aunque hasta ahora se ha planteado la expansión inusitada de la educación superior privada, esto no implica un proceso definitivo porque depende de las condiciones económicas de los estudiantes en un terreno de precaria estabilidad de la región. En Latinoamérica los cambios que está sufriendo el sistema universitario son más homogéneos que en otras latitudes y la aplicación de políticas educativas ha seguido una tendencia similar. Lo que puede observarse en conjunto es que la educación privada principalmente la de tipo lucrativo, sigue creciendo de manera desorganizada. Una hipótesis puede ser que ésta seguirá subsistiendo en tanto siga un fragmento de consumidores que paguen por ella, su límite es la capacidad de pago como cualquier otra mercancía y no gracias a los procesos de regulación gubernamentales. Este fenómeno no es exclusivo de Brasil es un tema general de la región.

\section{Chile}

En este escenario es imprescindible plantear el caso de Chile. Este país inició una reforma de la educación superior previa al resto de los países de la región. No obstante, las condiciones educativas, poblacionales y estructurales tienen ciertos matices que lo diferencian. En términos de rezago, existen 4 millones de personas mayores de 15 años que cursaron menos de 8 años de escolaridad. Aproximadamente 1.5 millones, esto es el $25 \%$, no ha completado la educación secundaria. La media nacional revela en la población masculina 9,6 años de escolaridad y en la población femenina 9,4 años. Los datos del 2001 sobre el analfabetismo muestran a 422.5 mil personas alfabetizadas, esto implica que el grado de analfabetismo afecta a menos del 5\% de la población económicamente activa. En este mismo año el gasto del PIB hacia la educación fue del $4,4 \%$ observándose también una distribución del gasto social del $26,8 \%$ y del gasto público del 18,7\% (OREAL-UNESCO-UIE, 2003: 110). La creación de instituciones universitarias públicas fue escasa, y se concentró desde 1980 en abrir nuevas modalidades no universitarias como centros profesionales y centros de formación técnica. La escalada de la inversión privada ha sido muy temprana y acelerada desde una década antes que otros países de Latinoamérica. Gajardo (2005: 163) sostiene que las universidades chilenas son de tres tipos:

1) Universidades Tradicionales. Son públicas y privadas que reciben aporte fiscal. Estas a su vez se dividen en Tradicionales Antiguas, que son aquellas ya establecidas antes de los ochenta (existen dos estatales y seis privadas) y en Universidades Derivadas, creadas desde 1981.

2) Universidades Privadas Autónomas. Creadas a partir de 1981, no reciben aporte fiscal y han alcanzado autonomía plena a partir de procesos de acreditación y examinación.

3) Universidades Bajo Supervisión. Son privadas, no reciben aporte fiscal y están bajo supervisión pues no han alcanzado los niveles de acreditación, por tanto no tienen completamente autonomía.

En el sistema chileno hay una diferenciación muy endeble entre el ámbito público y privado. Los aranceles son pagados por los estudiantes. En términos generales el financiamiento a las universidades públicas chilenas es estatal, sin embargo, no sobrepasa el $18 \%$ del presupuesto anual, significa que el $82 \%$ restante se autofinancia por otras vías ligadas al modelo de vinculación de la educación superior con el mercado (García Guadilla, 2001). A principios del siglo XXI existían en su sistema 252 
instituciones de educación superior: 66 universidades, 16 estatales, 9 privadas tradicionales, 41 privadas, 66 institutos profesionales y 120 centros de formación técnica. El mayor desarrollo se encuentra en las instituciones de régimen privado. Uno de los rasgos distintivos de la educación superior en Chile es que todas las instituciones, públicas o privadas cobran cuotas por derechos de matrícula y otros aranceles. Desde este punto de vista, el tema de la gratuidad educativa no es el elemento que distingue a instituciones públicas y privadas como en otros países. El cobro es prácticamente el mismo y en ambas se realizan pruebas de selección. De hecho, los niveles de complejidad en las pruebas son mayores en las universidades con aporte estatal pues los mecanismos de selección son mayores, caso similar al de México en este rubro. El sistema chileno está regido por un principio privatizador, que por una parte da paso a la creación de instituciones privadas y por otro reduce las aportaciones financieras a los espacios públicos. Una de las formas contradictorias más visibles es que los estudiantes que provienen de escuelas públicas, con menores recursos económicos, obtienen los menores puntajes en las pruebas de selección y terminan en universidades privadas. Los estudiantes provenientes de escuelas privadas con mayores niveles socioeconómicos obtienen por lo regular mayores puntajes en dichas pruebas, así las elites, realizan sus estudios profesionales en las universidades públicas (Gajardo, 2005).

El caso chileno tiene una dinámica distinta en sus procesos de privatización, no obstante se convirtió de cierta forma en un referente en las reorientaciones de las políticas de masificación de la educación superior para la región. En Centro América por ejemplo, un elemento indisoluble a considerar es la diversidad cultural y étnica, con una gran población indígena. Cerca del $50 \%$ de jóvenes en edad de asistir a la formación universitaria se encuentran en los límites de la pobreza. Honduras, Nicaragua y Guatemala se ubican dentro del mayor porcentaje de esta condición vulnerable (Bermúdez, 2007:147). No obstante la demanda por estudios superiores ha ido en ascenso principalmente en países como Costa Rica y Panamá que tienen un índice poco menor de jóvenes en pobreza. La información sobre el desarrollo de la educación superior en América Central es particularmente escasa pero aun así pueden encontrarse algunos datos que dan cuenta del crecimiento de la educación superior privada desde los noventa. Es necesario decir que aunque en Costa Rica por ejemplo, se impulsó la creación de algunas instituciones públicas nuevas y en Guatemala se masificaron las universidades públicas existentes, estas acciones no fueron suficientes para atender toda la demanda. El fomento la educación privada también fue la fórmula que acompañó las políticas de crecimiento del sistema superior, alcanzándose en todos los países centroamericanos una cobertura superior al 17\% (ISEALC, 2006). En este sentido hay que destacar la cobertura alcanzada por Panamá, pues cubre una de las tasas más altas de América Latina con el 50\% de cobertura, solamente después de Argentina. Incluso se destaca que de su población total en el sistema superior, el $60 \%$ corresponde al sector femenino (Bermúdez, op cit: 157).

Uno de los argumentos que ha justificado el impulso de la inversión del sector privado ha sido precisamente el de avanzar en la cobertura de la educación superior. Es probable que en algunos países de la región, la fórmula cumpliera su propósito. Sin embargo se encuentran países donde las condiciones socioeducativas y las reformas al sistema superior no han tenido los resultados esperados. Un claro ejemplo es el de México, donde si bien puede constatarse una ampliación de la cobertura en educación superior desde los ochenta, el problema del acceso al sistema ya sea público o privado es mucho mayor que hace 10 años. Incluso México cuenta con uno de los niveles de 
rezago más grandes de América Latina (Castillo, 2007: 203). Los siguientes datos generales permiten contextualizar el problema: en México existen cerca de 600 instituciones de educación superior privada más 137 escuelas normales (escuelas de formación para el profesorado) de tipo privado que suman más de 735 establecimientos en su conjunto. En términos de matrícula, el $66 \%$ se encuentra en instituciones públicas y el 34\% en instituciones privadas. La mayor concentración de estudiantes se encuentra en los estudios de pregrado distribuyéndose entre instituciones públicas y privadas. Aunque la educación que imparte el Estado es la dominante, existe una importante expansión en el ámbito privado, dada la contención del crecimiento en las instituciones públicas. Pero el crecimiento de las instituciones privadas, desde su propio origen, ha sido desigual. Uno de los aspectos que ha definido el desarrollo del ámbito privado ha sido su heterogeneidad, incluyendo el tema de la calidad de sus programas.

El acelerado crecimiento sin procesos mínimos de regulación trajo como consecuencia instituciones de diverso signo y con diferentes costos. Aún con ello siguen quedando muchos estudiantes fuera del sistema de educación superior. El crecimiento privado en la década de los noventa pasó de 1.1 millones a 8 millones a lo largo del periodo. Sin embargo, el número de excluidos pasó de 6.7 millones en edad de 20 a 24 años en 1990 a 8 millones en el año 2000. En 1990 por ejemplo, solamente se atendía al 13\% de la demanda, en 1999 aumentó al 17\%, y en el 2000 al 22\%. Pero a pesar del aumento en la cobertura, el número de jóvenes que están fuera del sistema también ha crecido: el índice de la deserción de las instituciones superiores es del 8.1\% (Castillo, op cit : 206). Este tipo de procesos dan cuenta de la complejidad que en algunos países han tenido las reformas a la educación superior. Uno de los puntos medulares que resaltan de los cambios en el sistema no solo en México sino en muchos países latinoamericanos es el desplazamiento hacia una lógica mercantil que está presente en buena parte de las instituciones privadas. Las repercusiones de éstas políticas no han pasado de largo en la opinión y en los bolsillos de quienes han tenido que pagar una educación de tipo lucrativo, es así como el despliegue de nuevos escenarios socioeducativos en el siglo XXI han mostrado ya signos cada vez más evidentes de resistencia ante los procesos de privatización educativa.

\section{A manera de cierre: polarizaciones y procesos de resistencia}

El crecimiento de la educación superior privada en América Latina presenta características contradictorias que son sintomáticas de una intención política hacia la homogenización y regulación general de los procesos educativos, especialmente del nivel superior. Es lo que en algunos casos se denomina "políticas de internacionalización", cuyo fin es estandarizar procesos de formación profesional que permitan adecuarse a las condiciones de la globalización y de intercambio económico. Aunque las instituciones privadas han tenido buena acogida a pesar de todo, no se ha dicho la última palabra en términos de su expansión. Los límites de su crecimiento son las propias condiciones económicas restringidas e inestables de la región. Baste señalar como ejemplo el caso mexicano donde durante el lapso de 2010 y 2011 la matrícula de instituciones privadas decayó en un 10\% según cifras proporcionadas por el Subsecretario de Educación Superior, Rodolfo Tuirán (Educación a Debate, 2011). 
41 El contexto de las movilizaciones evidentemente tiene sus particularidades en cada país pues responde a la trayectoria histórica de su propio sistema universitario. Sin embargo el rechazo hacia las políticas de expansión de oferta privada y contención de la ampliación de los espacios públicos ${ }^{13}$ han generado una percepción generalizada de desigualdad social y poca atención a la equidad en el acceso a la educación como un derecho social. Siguiendo con el caso mexicano, las cifras proporcionadas por la Subsecretaria de Educación Superior indican que aunque la cobertura es del $30.9 \%$ en todo el país, hay una disparidad porcentual local dentro de las entidades federativas que refleja serias desigualdades en el acceso y permanencia en el sistema, relacionadas con los niveles socioeconómicos, el contexto rural y urbano, y la propia disparidad interna en una misma entidad. El estado de Chihuahua es ejemplo de ello, en Ciudad Juárez se atiende solamente al 25.5\% y en Tijuana al 19.6\% (Educación a Debate, 2011). Si esta misma comparación la establecemos regionalmente pueden observarse amplios márgenes de diferenciación. Chile por ejemplo, tiene una cobertura en educación superior del 55\%, Argentina del 68\% y Cuba del 63\% por citar algunos casos (Rojas, 2011). Desde el año de 2006, México se encuentra entre los países miembros de la OCDE que asigna menor inversión por estudiante. El contexto de la polaridad de acceso a la educación superior y la inversión diferenciada han sido solamente un par de aspectos que han hecho compleja la reforma universitaria en Latinoamérica. Aquí me referiré brevemente solamente a dos esferas de tensión que aunque conformadas de manera distinta, representan espacios de movilización de la sociedad civil que pretenden incidir de alguna forma en la reformulación de la política educativa a nivel regional.

Una primera esfera es aquella compuesta por la oleada de movimientos iniciados a finales del siglo XX que cuestionaron la reorientación de las llamadas políticas neoliberales en la educación: algunos especialistas la han denominado como el "choque de las estrategias globales" (Ramos, 2000). El nuevo siglo fue un símbolo de nuevos escenarios sociales para los jóvenes latinoamericanos, donde la competencia, la diversidad, las aspiraciones democráticas, nuevas composiciones del empleo acompañadas de nuevas demandas formativas, marcaron una realidad que transfiguró los movimientos estudiantiles de la región. La figura del estudiante clásico proveniente de las élites se modificó radicalmente. Para Rama (2007: 41), las características tan heterogéneas del estudiante del siglo XXI impiden hablar de un movimiento estudiantil sino de diversos movimientos estudiantiles de demanda específica que en conjunto se diferencian entre sí. De esta manera hay movimientos que se definen por aspectos vinculados a las condiciones sociales y étnicas, hasta de tipo cultural y religioso que marcan una diversidad de expresiones sociales en medio del problema educativo. De este conjunto de movimientos tan complejos y distintos ha surgido un proceso de rechazo explícito a la privatización ${ }^{14}$ de la educación y la defensa de la educación pública. Este ha sido un proceso de organización transfronteriza que corre en toda América (Arriaga, 2011).

43 Se distinguen tres expresiones de rechazo hacia la reorientación de las políticas en la educación superior. La primera se resiste a la firma de tratados comerciales en los distintos países de América Latina, que colocan a la educación como un bien comercializable (Aboites, 2000). Esto implicó modificaciones específicas al ámbito jurídico que permitió una serie de inversiones nacionales e internacionales principalmente en el ámbito de la educación superior. La segunda rechaza la implementación de evaluaciones estandarizadas y pago al salario del docente por 
desempeño. Y finalmente se destaca un fuerte movimiento por la gratuidad de la educación y el acceso universal a la educación superior. En México pueden ubicarse diversos movimientos que provienen desde la década de los ochenta y que se potencializaron hacia finales de los noventa recobrando como ejes medulares precisamente los términos de la educación pública, gratuita y laica. Pero también deben señalarse los movimientos que anualmente organizan los jóvenes que quedan fuera de las instituciones públicas, al que se le ha denominado "movimiento de rechazados a la educación superior" (Arriaga, 2000:483).

Los movimientos que recogieron este tipo de demandas con el tiempo comenzaron a desplegarse por todo el continente. En Ecuador, a finales de los noventa se produjo un fuerte movimiento que planteaba el rechazo a las políticas económicas que vulneraban el sentido social de la universidad ecuatoriana. Colombia, Brasil, Argentina y Chile con mayor fuerza recientemente, se han incorporado a este conjunto de países movilizados. En Centro América las luchas han incorporado demandas anteriores vinculadas a los procesos de democratización, los casos son muy concretos en países como Honduras, Nicaragua, Guatemala y Costa Rica. Pero también en Estados Unidos pueden observarse movimientos de rechazo por el cierre de instituciones públicas, en específico sobresale el caso de Los Ángeles, donde se denunció la reducción salarial de los profesores, los recortes presupuestales y la transformación de las escuelas públicas a las denominadas charters schools (Coalición Trinacional, 2011). Algunos de los movimientos de resistencia que se desarrollaron en los noventa se transformaron en organizaciones que a lo largo del siglo XXI se han consolidado. Algunas de ellas son la Red Social para la Educación Pública en las Américas (Red SEPA), la Coalición Tri-nacional para la Defensa de la Educación Pública en Canadá, Estados Unidos y México, la Unión Nacional de Educadores de Ecuador, y la Federación de Organizaciones Magisteriales de Centroamérica (FOMCA), por mencionar algunos.

Solamente citaré las movilizaciones en México, Colombia y Chile, pero son ejemplares por diferentes razones. El movimiento en México en 1999 puede decirse que es el primer movimiento de gran magnitud que se expresó en la región, de rechazo frontal a las políticas internacionales y al tema de la privatización como su argumento central. El caso Colombiano es por su parte el movimiento triunfante, hasta el momento. Su gran movilización produjo un freno en la iniciativa de reforma que pretendía la incorporación de un sistema superior lucrativo. Y por último el caso Chileno cobra gran relevancia porque es un sistema que ya ha sido privatizado y que tras décadas de su implementación se producen las movilizaciones estudiantiles más importantes desde la dictadura, sobresale que a las calles han salido estudiantes de todo tipo incluyéndose los de las escuelas privadas.

\section{Mexico}

La Huelga de la Universidad Nacional Autónoma de México en 1999, fue uno de los primeros movimientos que inició con una oleada de inconformidad a las políticas neoliberales impuestas en América Latina. Es uno de los movimientos en la educación más importantes en la historia reciente de México. En éste proceso se distinguen dos grandes ámbitos de tensión: por un lado estrategias ligadas al proyecto político de fuerzas de derecha tanto en su esfera endógena como exógena y por otro lado representaciones tácticas de organización civil (estudiantil-universitaria) de resistencia en defensa a la universidad pública. Aunque en su origen la defensa del carácter público 
se asoció al pago de cuotas por derechos de matrícula, en el fondo también significó la defensa por el carácter autónomo y democrático de la universidad (Ramos, 2000). En éste sentido, fue un movimiento que logró contener la modificación al Reglamento General de Pagos, y con ello su impacto político tuvo gran fuerza a pesar de las tensiones internas del movimiento estudiantil.. Este movimiento no logró conformar "el movimiento" que lograra contener la avanzada de las políticas de reforma educativa con tendencia tecnocrática y empresarial, no obstante dejó algunas huellas que se articulan a los que le han seguido en la primera década del siglo XXI. Los movimientos recientes se ubican en la lucha por el aumento de la matrícula en la universidad pública y en el rechazo al sistema de crédito educativo. En este rubro existen coincidencias con otras movilizaciones del continente.

\section{Colombia}

En este sentido, en Colombia, se inició el movimiento con un proyecto de reforma al sistema de educación superior el cual planteaba la modificación a la Ley 30 de 1992, que se basa en su carácter público. El proyecto se presentó en 10 de marzo de 2011, y uno de los puntos que desató las mayores inconformidades fue el planteamiento que vulneraba el acceso equitativo a la educación superior. Entre otros aspectos no se planteó un incremento a los recursos financieros del sistema, ni mucho menos la creación de nuevas instituciones de carácter público, más bien el proyecto sustentaba el fomento de instituciones superiores privadas con fines de lucro. La gran movilización del 7 de abril, llevó a que el gobierno recule de esta posición cuatro meses después. Pero el tema de la reforma tuvo otras aristas fundamentales que fueron discutidas a lo largo del 2011, cuya máxima expresión quizá fue el paro del 3 de octubre con un mes de duración (Flores, 2011). Uno de los grandes aspectos que se encontraban en el centro de la discusión es la referente a la iniciativa del Crédito Educativo, que centralmente compromete las finanzas de los estudiantes y sus familias en una suerte de deuda educativa. Esta iniciativa beneficia principalmente a las universidades privadas garantizándoseles estudiantes/clientes cautivos, bajo la modalidad de cobro coactivo ${ }^{15}$ que garantice el cumplimiento de las deudas adquiridas por el servicio educativo. Este mismo tema también desató las movilizaciones en los primeros meses del 2012 en México.

Es importante destacar que en el tema de la autonomía universitaria en Colombia, como en México trastoca ámbitos como el del financiamiento. En este sentido, la responsabilidad financiera pretende ser disgregada a fuentes alternas lo cual implicaría una mayor penetración de agentes externos a las universidades que en un momento determinado tenderían a incidir en las políticas internas, tanto de gestión como académicas. En el caso colombiano la reconfiguración de los estatutos de financiación de las instituciones públicas, implicarían también la posibilidad de que éstas se pudieran declararse en Insolvencia Empresarial, tal como las instituciones privadas, dándoles un nuevo marco que haga, hasta cierto punto, indistintas en su operación y gestión a las universidades públicas y privadas. Esto permitiría en un momento dado la transferencia de recursos públicos a las instituciones privadas en un marco de competencia interinstitucional por recursos financieros.

El movimiento colombiano constituyó una fuerza social importante que se reflejó en los actos de entre octubre y noviembre, destacándose la Marcha de Antorchas, la Toma de 
Bogotá y la Jornada Continental de Movilización por la Educación, que hasta el momento indican un triunfo del movimiento, obteniéndose la promesa del presidente Juan Manuel Santos de eliminar la propuesta de Reforma a la Educación Superior. El punto a tomar en cuenta es que en algunos casos las reformas entran por la puerta trasera, es decir, en una aplicación de cambios sutiles que propician cambios aparentemente aislados y que por lo regular se dan de facto, por ejemplo, el otorgamiento de financiamiento por proyectos, evaluaciones por estándares de calidad, limitaciones en la provisión de recursos materiales y financieros, la limitación de apertura de plazas definitivas a concurso, la contratación de profesores por horas, la firma de convenios entre empresas e instituciones públicas y viceversa, la existencia de agencias de seguros que financian estudios en instituciones de paga, la exención de impuestos en algunos rubros de la educación privada que entre otros implican el apoyo constante a sus intereses, el aumento de establecimientos privados frente a la inmovilización de la matrícula pública, etc.

\section{Chile}

Las movilizaciones en Chile del 2011, por otra parte, coincidieron temporalmente con las realizadas en Colombia. Lo relevante en este caso es que el sistema chileno se caracteriza por ser dominantemente privado y aunque le anteceden movilizaciones como la del 2006, las que transcurrieron entre mayo y noviembre del 2011 son consideradas las más importantes desde la dictadura pinochetista. Aunque la principal consigna fue por una educación pública y gratuita de calidad, desde el inicio del movimiento se incorporaron demandas sociales más amplias que impactaron en una buena acogida por parte de sectores diversos de la sociedad. La respuesta del gobierno hacia un mes de paro de labores académicas fue la reformulación del sistema de crédito educativo, implementado en este país desde hace tiempo, propuesta que no fue aceptada por los comités del movimiento. Conforme fue avanzando el movimiento, se incorporaron por primera vez estudiantes de instituciones privadas: esto significó en realidad una movilización de todo el sistema. Una de las demandas implicaba la igualdad de oportunidades de acceso al sistema por capacidades y no por recursos económicos. Es una demanda común pero en condiciones distintas. En otros países la educación es mayormente pública y gratuita sobretodo (caso mexicano) y el acceso a estos espacios es insuficiente pretendiendo derivarse a la escuela pagada. En Chile la mayoría de los estudiantes se ubica en escuelas privadas, aquí la idea es que la educación no sea un bien transable. Las demandas se pueden resumir entonces en: 1) reforma al sistema de acceso que asegure la igualdad de oportunidades, 2) aumento al gasto público, 3) democratización del sistema. En estas tres hay diversas argumentaciones entre las que destacan, la prohibición de establecimientos lucrativos, educación superior gratuita, reforma tributaria que garantice el aumento de la financiación en el sistema (Smink, 2011). Como todo movimiento ha tenido sus escaladas y descensos, pero aun no está dicha la última palabra. Lo que puede decirse es que todas estas expresiones de rechazo y resistencia a las reformas universitarias hablan no solo de posicionamientos ideológicos per se, no es tan simple. Es un problema de dimensiones sociológicas y culturales donde el sujeto educativo se constituye a partir de la interpelación política que realiza a un Estado impositivo. En medio de este proceso se intercalan si bien ideologías, también imaginarios e historia, elementos concomitantes al desarrollo de la universidad latinoamericana y a su papel social. 
51 En ésta arena de disputa, los ámbitos de presión tienen distintos rostros. Estamos frente a una segunda esfera emergente, conformada por diversas organizaciones política e ideológicamente opuestas a las señaladas anteriormente. Estos organismos se encuentran vinculados a grupos empresariales, cuyas acciones se basan en la premisa de una "educación de calidad". Y aunque no es el propósito del presente artículo desarrollar la discusión sobre éste fenómeno, es relevante señalar por lo menos, que en Brasil se inició en septiembre de 2011 la llamada Red Latinoamericana de Organizaciones de la Sociedad Civil por la Educación, bajo el apoyo del Banco Interamericano de Desarrollo (BID). Actualmente integra a 13 países: Argentina (EducAr 2050), Brasil (Todos pela Educaçao) Chile (Educación 2020), Ecuador (Grupo Faro), El Salvador (Fundación Empresarial para el Desarrollo Educativo), Guatemala (Empresarios por la Educación) Honduras (Fundación por la Educación Ernesto Maduro), México (Mexicanos Primero), Panamá (Unidos por la Educación), Paraguay (Juntos por la Educación), Perú (Empresarios por la Educación), y República Dominicana (Acción por la Educación). Estas organizaciones parten de un proyecto de similares estrategias cuyo fin es incidir en todos los niveles educativos a partir de tres mecanismos de presión: la comunicación y la movilización a partir de la utilización de los medios de información, producir estudios e informes de alta calificación, y la búsquedad de articulación directa con los gobiernos (Moreira, 2012: 40). Es un movimiento que cuenta con grandes recursos financieros para su despliegue, y aunque sostienen que no persiguen la privatización de la educación pública, sí el fomento de trabajadores más calificados para elevar la competitividad de la región. En México pueden observarse diversas acciones directas cuyo principal objetivo es legitimarse como organización socialmente válida que goce de un amplio consenso, de manera que ésta organización sea quien "lleve la voz" de los intereses de la sociedad mexicana ${ }^{16}$.

En este gran conjunto de procesos complejos que implican movilizaciones por diversos frentes, la reorientación de las políticas educativas en la región hacia la elevación de la cobertura a partir del fomento de instituciones privadas con fines de lucro en detrimento de la calidad de los servicios es clara : este argumento se aprecia tanto en las organizaciones de resistencia a la privatización, como en las organizaciones vinculadas a los empresarios. Éste es un factor nodal que ha sido estudiado por especialistas en la región quienes insisten en el problema de una política pública basada en la ampliación de negocios educativos con una supervisión y regulación escasa (ver entre otros, los trabajos reunidos en las respectivas compilaciones de Rollin Kent y Pablo Gentili). Es importante destacarlo aquí porque si se hace una revisión más fina de las demandas de cada uno de los movimientos desatados en los años recientes puede verse como un elemento común.

53 Es importante reconocer que hay un proceso latente, de diferentes magnitudes que ubica el tema de la privatización como un aspecto nodal de diversas organizaciones civiles y grupos en toda América, y que por lo tanto han constituido un gran movimiento internacional de corte democrático por el derecho a la educación, pero una educación pública y gratuita que intenta recoger los principios con los que se construyó el ideal de la educación latinoamericana. Una educación cuyo espíritu se basa en un derecho social, intransferible y no mercantilizable como principio básico. Los movimientos de resistencia de los meses recientes marcan nuevas rutas de discusión que permiten dimensionar con nuevos referentes los procesos de expansión de la educación superior privada no solo en América Latina, sino en el mundo. 


\section{BIBLIOGRAPHIE}

Aboites H., Viento del Norte. TLC y privatización de la Educación Superior en México, México, UAM/

Plaza y Valdés, 2000.

ANUIES, Anuario Estadístico 2003. Licenciatura en Universidades e Institutos Tecnológicos, México, 2003.

ANUIES, Anuario Estadístico 2003. Licenciatura en Universidades e Institutos Tecnológicos. Resumen y series históricas, México, 2003.

ANUIES, Anuario Estadístico 2003. Licenciatura en Universidades e Institutos Tecnológicos. Población Escolar por Entidad, Institución, Escuela y Carrera, México, 2003.

ANUIES, Anuario Estadístico 2003. Población Escolar de Postgrado, México, 2003.

Banco Mundial, Gasto público en educación, total (\% del gasto del gobierno). Consultado el 10 de abril de 2012.

http://datos.bancomundial.org/indicador/SE.XPD.TOTL.GB.ZS/countries

Banco Mundial, Inscripción escolar de nivel terciario (\% bruto), 2007-2011. Consultado el 10 de abril de 2012.

http://datos.bancomundial.org/indicador/SE.TER.ENRR

Bresser-Pereira L., "Reforma de la Nueva Gestión Pública: ahora en la agenda de América Latina, sin embargo..." en International Journal of Political Studies, no. 3, 2001.

Castillo Berthier H., "Juventud y educación en México. Algunos elementos para su caracterización" en Educación superior en América Latina y el Caribe: Sus estudiantes hoy, Colección Idea Latinoamericana, Unión de Universidades de América Latina y el Caribe, México, 2007, págs. 187-234.

Castro Ríos E. y Vázquez Maldonado K., Análisis y síntesis del Informe sobre la Educación Superior en América Latina y el Caribe 2000-2005. La metamorfosis de la educación superior, IESALC-UNESCO, 2006.

Cazés D., Ibarra E. y Porter L. [Coords.], Las universidades públicas mexicanasen el año 2030: examinado presentes, imaginado futuros, México, UAM/UNAM, 2010.

Coalición Tri-nacional en defensa de la Educación Pública, 2011. Consultado el 29 de septiembre de 2011.

www.trinational-usa.org

De Garay A., "Las Universidades Tecnológicas, un subsistema estancado" en Educación a Debate, México, 11 abril de 2012. Consultado el 12 de abril de 2012.

http://educacionadebate.org/2012/04/11/las-universidades-tecnologicas-un-subsistemaestancado/

De la Luz Arriaga Lemus M., "Integración económica y educación, nuevas tendencias en América del Norte" en N. Klahn, A.Alvarez, F.Manchón, P.Castillo [comps.], Las nuevas fronteras del siglo XXI, México, La Jornada ediciones, UNAM, UAM, Chicano/Latino Reserch Center,University of California, Santa Cruz, 2000.

De la Luz Arriaga M., "Resistencia y alternativas continentales, a las políticas educativas privatizadoras promovidas por los organismos internacionales" en Guadalupe Olivier [coord.], Privatización, cambios y resistencias en la educación. Hacia la demarcación de escenarios en la educación pública y privada en la primera década del siglo XXI, México, UPN, 2011. 
Dietrich S. H. [coord.] Identidad, Educación y Cambio en América Latina, México, UAM, 2005.

Educación a Debate, "Disminuye matrícula en universidades privadas", 2011. Consultado el 2 de abril de 2012.

http://educacionadebate.org/2011/11/04/7654834/

El Espectador (25 de agosto de 2011), Editorial: Sin ánimo de lucro. Consultado 2 de abril de 2012. http://www.elespectador.com/impreso/temadeldia/articulo-256119-universidades-animo-delucro-apuesta-del-gobierno

El Tiempo (Colombia) (23 de agosto 2011), Gobierno retira artículo que permitiría el lucro en la educación superior. Consultado el 10 de abril de 2012.

http://www.eltiempo.com/vida-de-hoy/educacion/ARTICULO-WEB-

NEW_NOTA_INTERIOR-10212947.html

Flores J., "El movimiento estudiantil en Colombia" en La Jornada (22 de noviembre de 2011). Consultado el 10 de abril de 2012.

http://www.jornada.unam.mx/2011/11/22/opinion/a03a1cie

Gajardo T., "Educación privada vs. Educación pública en Santiago de Chile: una reflexión necesaria”, en Pablo Gentili y Bettina Levy [comps] Espacio público y privatización del conocimiento. Estudios sobre políticas universitarias en América Latina, Buenos Aires, Argentina, CLACSO, 2005.

García Guadilla C., "Lo público y lo privado en la Educación Superior. Algunos elementos para el análisis del caso latinoamericano" en Revista de Educación Superior, México, No. 119, julioseptiembre, 2001.

Gentili P., Frigotto G., Leher R., Sturbin F., [Comps], Políticas de privatización, espacio público y Educación en América Latina, Argentina, CLACSO/Homo Sapiens, 2009.

Gentili P. y Levy B., Espacio público y privatización del conocimiento. Estudios sobre políticas universitarias en América Latina, Buenos Aires, Argentina, CLACSO, 2005.

Hall G. y Patrinos H. A., Pueblos indígenas, pobreza y desarrollo humano en América Latina, Banco Mundial/Mayol Ediciones, 2005.

IESALC-UNESCO, “Informe sobre la educación superior en América Latina y el Caribe, 2000-2005”, Caracas, Venezuela, Ed. Metrópolis, 2006.

Instituto de Educación Superior de América Latina y el Caribe (IESALC). Boletín Digital No.118, de 25 de marzo - 7 de abril de 2006.

Kent R. [Comp.], Los temas críticos de la educación superior en América Latina en los años noventa. Estudios Comparativos, México, FLACSO/Universidad Autónoma de Aguascalientes/FCE, 2002.

Krotsch P., La universidad cautiva, Argentina, La Plata: Al Margen, 2002.

López Segrera F., Escenarios Mundiales de la Educación Superior. Análisis Global y Estudios de Casos, Argentina, CLACSO, 2006.

López Segrera F., "La universidad latinoamericana y los procesos de internacionalización: las estrategias de financiamiento", en Pablo Gentili [et al], Políticas de privatización, espacio público y educación en América Latina, Argentina, CLACSO, 2009, págs. 239-264.

Mönckeberg M. O., El negocio de las universidades en Chile, Santiago de Chile, Random House Mondadori/Debate, 2007.

Moreira Martins E., "Se amplía red vinculada con empresas para incidir en políticas de educación” en La Jornada, entrevista de Laura Poy Solano, México, 2012, pág. 40. 
Masís Bermúdez J. A., "La juventud de Centroamérica” en Educación superior en América Latina y el Caribe: Sus estudiantes hoy, Colección Idea Latinoamericana, Unión de Universidades de América Latina y el Caribe, México, 2007, págs. 125-186.

Olivier G., "La década de los noventa: cúspide de la educación superior privada mexicana en el siglo XX”, México, Universidad Pedagógica Nacional-Colección Más Textos, 2007, págs. 201-220.

Olivier G., "Reconfiguración del escenario educativo mundial: ¿podemos hablar de tendencias hacia la privatización?", en Guadalupe Olivier [coord.], Privatización, cambios y resistencias en la educación. Hacia la demarcación de escenarios en la educación pública y privada en la primera década del siglo XXI, México, UPN, 2011.

Plotkin M. B., La privatización de la educación superior y las ciencias sociales en Argentina, Argentina, CLACSO, 2006

Rama C., "El nuevo escenario de la Educación Superior Privada en América Latina”, 2011. Consultado el 30 de septiembre de 2011.

http://www.histedbr.fae.unicamp.br/revista/edicoes/40/art01_40.pdf

Rama C., "Los nuevos estudiantes en circuitos diferenciados de educación" en Educación superior en América Latina y el Caribe: Sus estudiantes hoy, Colección Idea Latinoamericana, Unión de Universidades de América Latina y el Caribe, México, 2007, págs. 13 a 42.

Ramos A., La huelga de la UNAM en el contexto de una crisis de coyuntura (1997-2000), México, 2010. Consultado el 3 de abril de 2012.

http://www.tlahui.com/politic/politi00/politi10/mx10-15.htm

Rojas H., "Reconoce SEP desigualdades en educación superior" en Educación a Debate, 2011. Consultado el 7 de abril de 2012.

http://educacionadebate.org/2011/11/04/reconoce-sep-desigualdades-en-educacion-superior/

Schwartzman S., "O financiamento de ensino superior no Brasil na década de 90" en Arrosa Soares, M. (coord.) Educacão Superior no Brasil, Caracas: IESALC/ UNESCO, 2002.

Sepúlveda P., "Inequidad educativa tiene más nudos en Chile” (5 de agosto de 2011), IPS. Consultado el 2 de abril de 2012.

http://www.ipsnoticias.net/nota.asp?idnews=98814

SITEAL, “Base de Datos", 2011. Consultado el 01 de octubre de 2011.

http://www.siteal.iipe-oei.org/

SITEAL, “Cobertura Relativa de la Educación Pública y Privada en América Latina”, 2011.

Consultado el 01 de octubre de 2011.

http://www.cedus.cl/files/

Cobertura\%20relativa\%20de\%20la\%20educaci\%C3\%B3n\%20p\%C3\%BAblica\%20y\%20privada\%20en\%20Am\%C3\%A9rica\%20Latina.pdf

Smink V., "Las razones de las protestas estudiantiles en Chile" (miércoles 10 de agosto de 2011), BBC Mundo. Consultado el 2 de abril de 2012.

http://www.bbc.co.uk/mundo/noticias/2011/08/110809_chile_estudiantes_2_vs.shtml

Stallivieri L., "O Sistema de Ensino Superior do Brasil características, tendências e perspectivas" en Educación superior en América Latina y el Caribe: Sus estudiantes hoy, Colección Idea Latinoamericana, Unión de Universidades de América Latina y el Caribe, México, 2007, págs. 79-100.

Zebadúa E., "La educación, ¿gasto o inversión?, en Educación a Debate, 2011. Consultado el 7 de abril de 2012.

http://educacionadebate.org/2011/11/07/la-educacion-\%C2\%BFgasto-o-inversion/ 


\section{NOTES}

1. Desde una perspectiva crítica, destacan varios textos que abordan sobre el tema la educación privada en la región en el marco de estudios sobre la implementación de políticas neoliberales en América Latina y en México en específico, . Entre ellos se encuentran los siguientes:

Altbach, Philip (2002), Educación superior privada, México, CESU-UNAM/Miguel Ángel Porrúa; Balán, Jorge y Ana María García Fanelli (2002), "El sector privado de la educación superior" en Rollin Kent (comp.), Los temas críticos de la educación superior en América Latina en los años noventa. Estudios comparativos, México, Fondo de Cultura Económica/ FLACSO-Chile/ Universidad Autónoma de Aguascalientes; Barrón Tirado, Concepción (2002), Universidades Privadas. Formación en educación. México, UNAM-CESU/Plaza y Valdés; Didou, Sylvie (2006), "Internacionalización de la educación superior y provisión transnacional de servicios educativos en América latina: del voluntarismo a las elecciones estratégicas" en Claudio Rama [ed) Informe sobre la educación superior en América Latina y el Caribe 2000-2005, IESALC; García Guadilla, Carmen, "Access to Higher Education: between Global Market and International and Regional Cooperation", UNESCO Forum Colloquium on Research and Higher Education Policy, 1-3 de diciembre de 2004, pág.11; Daniel Levy (1986) La educación superior y el Estado en Latinoamérica. Desafíos privados al predominio público. México, CESU/ Miguel Ángel Porrúa; Olivier, Guadalupe (2007) Educación superior privada en México. Veinte años de expansión: 1982-2002, México, Universidad Pedagógica Nacional/ SEP, Colección Más Textos;(2007).

2. La Reforma de Córdoba aconteció en la Universidad Nacional de Córdoba, en Argentina. Es el producto de uno de los movimientos estudiantiles más relevantes de la historia universitaria en América Latina. Influyó de manera determinante en otros movimientos estudiantiles universitarios de la época en diversos países. Entre ellos se encuentra la de la Universidad Nacional de México: a propósito de los debates que surgieron en la universidad Argentina, se logró la autonomía universitaria de esta universidad tal como la conocemos hasta hoy en día: Universidad Nacional Autónoma de México.

3. Aunque en diferente medida, países como México, Brasil, Guatemala, Venezuela, Perú, Colombia, Bolivia, Ecuador y Chile se destacan por haber implementado políticas de atención e incorporación al sistema de educación superior a estudiantes provenientes de grupos indígenas.

4. Este índice mide la desigualdad en la distribución del ingreso y el consumo.

5. Cabe decir como un ejemplo que en México la distribución del ingreso por salario es sumamente heterogénea, buena parte de la población tiene ingresos de dos a cuatro salarios mínimos. Se encuentran otros fragmentos de la sociedad que alcanzan hasta los ocho salarios mínimos. En términos concretos un salario mínimo es equivalente a 5 dólares aproximadamente al día, esto significa en el mejor de los casos el ingreso familiar es de 1,120 dólares mensuales. El salario de la clase trabajadora difícilmente permite el acceso a una educación privada.

6. Evidentemente hay que matizar sobre el tema de las distintas ofertas tanto públicas y privadas existentes en Estados Unidos, en función de sus costos y también de su prestigio académico, pues en efecto existen instituciones privadas muy costosas pero también otras públicas más caras que las denominadas "universidades garaje", no obstante este aspecto rebasa los propósitos del presente trabajo.

7. Los datos que ofrece el autor corresponden al primer quinquenio del siglo XXI, no obstante establece ciertas proyecciones respecto a la tendencia que ha presentado el comportamiento tanto del ingreso per cápita como el crecimiento de la matrícula que permite establecer un rango 
más o menos aproximado, que da una idea de de la proporción del esfuerzo familiar-individual por el sostener estudios superiores.

8. La Universidad Autónoma de Santo Domingo (UASD), tiene más del 30\% de su matrícula total en ocho sedes que están fuera de la capital.

9. De la misma forma que la UASD, La Universidad Nacional Autónoma de México (UNAM) tiene al $30 \%$ de su matrícula fuera del Distrito Federal.

10. Este periodo coincide con la última dictadura militar de ese país.

11. Significa la aplicación de recursos públicos a las instituciones privadas a partir de la asignación de créditos financieros a estudiantes de bajos recursos.

12. El tipo de exención fiscal puede ser sobre el impuesto sobre la renta y las contribuciones con fines de seguridad social, las filantrópicas además deben demostrar que se dirigen a servicios públicos y que aplican sus recursos en el mantenimiento operativo y en el desarrollo de sus objetivos institucionales. Esto al mismo tiempo les permite hacer descuentos a sus estudiantes de bajos recursos en becas que van desde el $50 \%$ al $100 \%$.

13. La contención de la inversión pública no significa que el Estado no otorgue financiación a la educación, significa en todo caso que la proporción de ésta no cubre las expectativas de la demanda. Por ejemplo, la inversión educativa total en el gobierno mexicano para el año de 2012 es del 3.75\% del Producto Interno Bruto (PIB), es un monto inferior al otorgado en 2011 que ascendió a 3.8\% y al de 2010 del 3.9\% a pesar de que la Ley General de Educación en su artículo 25, marca como obligación del Estado asignar el 8\% del PIB a los servicios educativos (Zebadúa, 2011). $Y$ aunque es necesario señalar que se han creado instituciones superiores como es el caso de las 11 Universidades Interculturales creadas desde el finales del siglo XX a la fecha, solamente tres de cada diez indígenas tiene posibilidad de ingresar a la educación universitaria y aunque también se han creado algunas instituciones principalmente de corte tecnológico, la mayor parte de la demanda se ubica en la UNAM. En ésta institución menos del 10\% de los aspirantes obtienen un lugar en alguna de sus carreras (La Jornada/2 abril 2012, p.40). Un elemento a destacar es que el resto de las instituciones de educación superior existentes en México tampoco logran compensar, de manera importante, el alto número de aspirantes que quedan fuera del sistema. La alternativa de crear instituciones de corte tecnológico, desde la década de los noventa del siglo pasado, tampoco fue la panacea. La proporción que atiende a nivel nacional es de tan solo el $3 \%$. Según Adrián De Garay (2012), hay una cultura arraigada en la que es importante para los jóvenes estudiar preferentemente una licenciatura que una carrera técnica.

14. En este contexto se entiende como privatización de la educación no solamente al proceso de expansión de las instituciones de tipo privado, producto de la restricción financiera de la universidad pública y de las reformas impulsados por el Estado para apoyar la inversión de particulares. También alude al conjunto de acciones deliberadas desde los gobiernos hasta grupos empresariales y privados que se disputan la influencia en las instituciones incluyendo la pública, sometiéndola a sus intereses y orientaciones. Significa que cuando se establece el término de privatización se refiere a dos procesos diferenciados: la presencia creciente de establecimientos de tipo privado y los procesos que le dieron lugar, y la reorientación con nuevos referentes para su la conducción de las instituciones púbicas en un contexto generalizado de mercantilización de la vida social (Olivier, 2011).

15. Implica la intervención del Estado para que el cobro sea efectuado conforme a lineamientos y posibles sanciones en caso de incumplimiento. Básicamente implica lo que se denomina jurisdicción coactiva es decir, la potestad jurisdiccional que se asigna a entidades públicas, para que por sus propios medios, hagan efectivas las obligaciones que legalmente se causen a su favor.

16. Con un gran despliegue publicitario y con una permanencia inusitada en las salas de cine se ha proyectado la película "De panzazo", es en realidad un documental que contiene una severa 
crítica al sistema de educación básica, principalmente a su sindicato (SNTE) y al profesorado culpabilizándolos del rezago educativo en el país. Ninguna película nacional ha tenido en las últimas décadas tanta difusión en los medios. Es una producción de la organización Mexicanos Primero y ha gozado del respaldo de uno de los grupos monopólicos más fuertes sobre los medios de comunicación en México: Televisa.

\section{RÉSUMÉS}

En la década de los noventa del siglo XX se desarrolló el proceso más importante de cobertura del sistema de educación superior en América Latina. Uno de los sectores de mayor crecimiento en éste proceso fue el de las instituciones de tipo privado, dándose con ello un giro fundamental a la configuración histórica de éste sistema en la región. La fuerte demanda por estudios profesionales, la nueva composición de estudiantado, las políticas de retracción de la inversión pública en el ámbito universitario, las modificaciones jurídicas en el tema educativo, las firmas de tratados comerciales y la fuerza de un contexto internacional tendiente a reformar al sistema de educación superior, fueron tan solo algunos elementos que dieron paso a la expansión de las instituciones privadas. Los establecimientos que comenzaron a surgir en Latinoamérica, su diversificación, estructura organizacional y pedagógica, así como nivel de presencia en cada país, reflejan la gran heterogeneidad social en la región. Los mayores porcentajes de crecimiento tanto de la matrícula como de las instituciones se ubican en el sector privado y aunque en general la oferta pública sigue siendo el espacio de mayor cobertura, en algunos contextos se vislumbra un crecimiento sostenido del sector privado tendiente a empatar con el servicio público. La mayor parte de las instituciones de reciente creación son de tipo lucrativo y esto ha dado también una nueva caracterización al comportamiento del sistema de educación superior latinoamericano.

Las instituciones vinculadas a la dinámica del mercado tienen ciertas limitaciones en contextos económicos vulnerables como el de América Latina, esto significa un elemento importante en el terreno de las políticas de masificación de la educación superior que pretenden ampliarse a través de la inversión privada. La fuerte demanda por estudios superiores y las dificultades de acceso tanto en el ámbito público como en el privado son los elementos que se encuentran en el centro de la tensión. Se reconoce, en este sentido, la existencia de condiciones precarias que hacen del acceso a la educación superior uno de los temas nodales en las agendas de los gobiernos, donde la orientación hacia el fomento de instituciones privadas no lo ha resuelto por completo. La desregulación del sistema privado ha caracterizado la dinámica de expansión en la región, lo que en corto tiempo dio lugar a la presencia de un fragmento muy grande de establecimientos de baja calidad vinculados al mercado. La forma en la que se orientó el desarrollo de las instituciones de educación superior privada y las reformas hacia la universidad pública produjeron reacciones importantes en toda la región. La aplicación de políticas de privatización, en distinta medida, generó movimientos de resistencia que propugnan por una educación pública, gratuita, laica e incluyente como los componentes fundamentales de la educación latinoamericana.

The most important coverage of higher education system developed in Latin America since the 90's decade of the Twentieth Century. One of the most growing sectors in this period was that of private institutions, shifting the historical structure of the educational system in the region. Several elements show this path: a strong increasing demand for professional education, a new 
student constituency, the retreatment public policy at the higher educational field, legal educational reforms, free trade agreements among countries, and the impact of the international setting that deeply impact higher educational system.

New social scenery defined a great mixture of private educational businesses that were emerging all around Latin America countries. Large social segregation mirrored specific business diversity, both organizational and educational structures, as well as the level of attendance in every country. Larger percentage of growth, both in educational recruitment and of institutions, has been situated in the private sector. Although the public supply is still a very often a large coverage, in some regional contexts a sustained growth of the private sector, that almost equal public supply, is revealed. Most of new private institutions are profitable-oriented businesses. This whole situation has motivated among scholars a new definition for higher educational performance.

Those institutions that are linked to market dynamics have, however, some limits, especially in vulnerable economic contexts, such as Latin America. This circumstance turns in an important constituent in the realm of massive policies of higher education, to be broader through private investment. The strong demand for higher education, and accessibility difficulties, both to public and private institutions, are social aspects frequently in political strain.

We have to recognize, notwithstanding, the existence of poor conditions that make accessibility to higher education the nodal theme for governmental agendas. The course taken by private institutional promotion has not solved this situation efficiently. Deregulation for the private system has defined the expansion dynamic in the region. This has leaded in a short period of time the presence of a larger portion of low quality private higher education businesses, tied to the market. The way these private institutions were oriented as well as the approved public educational reforms forced to important social collective actions. Privatization policy application, in some degree, resulted in resistance movements claiming for fundamental constituencies in order to have a qualified education: public, free, secular and inclusive.

\section{INDEX}

Keywords : Private Higher Education, Latin American University System, expansion, resistance, educational policies, educational reforms, Latin American social and educational conditions.

Palabras claves : Educación superior privada, sistema universitario latinoamericano, expansión, resistencias, políticas educativas, reformas educativas, condiciones socioeducativas latinoamericanas.

\section{AUTEUR}

\section{GUADALUPE OLIVIER}

Socióloga, Doctora en Pedagogía por la UNAM, Coordinadora de Sociología de la Educación en la Universidad Pedagógica Nacional, Ciudad de México, mariao969@yahoo.com.mx 